\title{
DEICTIC AND OTHER GESTURES IN INFANCY
}

\section{DEÍCTICOS Y OTROS GESTOS EN LA INFANCIA}

\author{
ULF LISZKOWSKI ${ }^{1,2}$ \\ ${ }^{1}$ Max Planck Research Group Communication Before Language, Max-Planck-Institute for \\ Psycholinguistics, Nijmegen, The Netherlands; \\ ${ }^{2}$ Donders Institute for Cognition, Brain and Behaviour, Radboud University, Nijmegen, The Netherlands. \\ Ulf.Liszkowski@mpi.nl
}

\begin{abstract}
The paper reviews studies on prelinguistic infants' gestures and the evidence for deictic and for symbolic gestural communication before language. First, recent and new studies demonstrate that prelinguistic infants communicate in complex ways with deictic gestures, in particular pointing, and that pointing is closely related to the emergence of language. These ontogenetic findings thus support gestural origins and social-pragmatic accounts of human communication and show that human communication emerges first in deictic gestures and is based on social-cognitive and motivational skills that run much deeper than language alone. Second, however, a review of other, non-deictic gestures suggests that prelinguistic infants use these other gestures initially low-frequently, non-representationally, and with little or no direct relation to language. These findings qualify gestural origins accounts and suggest, based on the cognitive complexities underlying the symbolic use of manual actions, that fully representational gestures instead emerge after, or even because of language, and possibly as co-speech gestures. The review of the evidence both supports and challenges gestural origins accounts of language and provides a differentiated perspective on gestures in the ontogeny - and likewise evolution - of language.
\end{abstract}

\section{Key Words}

Gestural communication; social cognition; pointing; symbol use.

\section{Deictic and other gestures in infancy}

Infants communicate with various kinds of gesture. Gestural origins accounts of human communication posit that language evolved from manual actions and gestures (e.g., Armstrong \& Wilcox, 2007; Arbib, 2005; Corballis, 2002; Tomasello, 2008; Capirici et al., 2005). Social-pragmatic theories of human communication emphasize that language-usage and acquisition crucially rely on prior social-cognitive and cooperative abilities (Grice, 1957; Sperber \& Wilson, 1986; Bruner, 1983). Infants' gestural communication is a test case for these ideas. How do infants use gestures to communicate in meaningful ways before they have any language? With regard to the gestural origins accounts, the questions are: What are the kinds of gesture that young infants use, and how do they emerge in relation to language? For example, a strong prediction would be that infants first communicate fully with gestures, and then spoken language supplants previous gestural forms. With regard to social-pragmatic theories, the question is: What are the cognitive com- 
plexities underlying infants' early gesture use? For example, a strong prediction would be that the social-cognitive and symbolic skills of human communication are present already before language and first revealed in infants' gestural communication. In the current paper I review the ontogenetic evidence pertaining to gestural and social-pragmatic origins accounts of human communication. Based on the available evidence I will argue that only specific forms of gesture may have preceded language, while others in fact may have followed; and that while most of the key cognitive prerequisites for human communication are indeed revealed through prelinguistic gestures, others may still emerge after language.

Many of the quotidian gestures in adult communication are culture-specific and conventionalized. For example, while thumbs-up means 'good luck' in the US, it means 'screw you' in Iran (e.g., Archer, 1997). These gestures work thus like symbolic codes that one has to learn, just like any other agreed upon signal. Many gestures are representational in that they re-present in one or another way the intended referent. But from an ontogenetic perspective on gestural origins, the question is not only whether gestures are learned and produced earlier or more easily than spoken language. The ontogenetic puzzle is that to acquire even these gestures, one already has to have quite some communicative and cognitive skills to understand what it is that they code (see Quine, 1960). The cognitive argument is thus that there must be some more natural forms of gestural communication that run much deeper than language alone and enable acquisition of linguistic - and gestural - codes in the first place. Thus, apart from a possible modality advantage of gestures over spoken language, we still need to tease apart within the gestural modality more natural from more codified types of gesture.

Of particular interest are deictic gestures, like pointing or showing. Deictic gestures work through ways of presenting others with an aspect in the environment. The same gesture can be used for an infinite set of referents, and the same act can be used in many diverse ways - because one can present a referent for many different reasons. This kind of flexibility is striking and must be very useful if we entail a world of communication without any words or other codes at hands. However, this flexibility comes at the cost of fairly advanced social-cognitive and cooperative skills. Precisely because of the lack of any inbuilt 'meaning', deictic gestures require one to draw inferences about the interlocutor's behavior within a shared situation ('common ground' or 'joint attentional format'; see Clark, 1996; Bruner, 1983). What aspect of the environment has the interlocutor in mind? Why does the interlocutor indicate that aspect? Crucially, does the interlocutor go through these inferences because of the communicative act? This tripartite of intentionality involving respectively referential, social, and communicative intentions is part and parcel of deictic gestural communication (Tomasello, Carpenter \& Liszkowski, 2007). The question is to what extent infants' gestures already share the social and cognitive complexities of the adult version of this communicative act. When and how in development do these gestures and their underlying complexities emerge, and how do they relate to the acquisition of a first language?

\section{Deictic gestures in infancy}

Infants begin to use deictic gestures such as showing (i.e. holding up an object) and pointing (extending the arm with or without an extended index-finger in the direction of an object) towards the end of the first year of life. Most of the research has focused on the pointing gesture (Bates, Camaioni, and Volterra, 1975; Leung \& Rheingold, 1981; Murphy, 1978). Bates and colleagues originally conceptualized pointing as a kind of social tool use, and distinguished two types of pointing. In proto-imperative pointing infants use the adult as a tool to obtain an object. In proto-declarative pointing infants use the object as a tool to obtain adult attention. Camaioni (1993) proposed that protoimperative gestures only require the infant to understand the other as a causal agent - not a mental agent - who makes things happen behaviorally, whereas proto-declarative gestures require the infant to understand the other as a mental agent whose attention may be directed to external entities (see also Baron-Cohen, 1989). Moore and colleagues (e.g., Moore \& 
D'Entremont, 2001) have taken a more thoroughgoing lean position and claimed that even proto-declarative gestures are initially not directed at the mental states of others, but simply used to gain adult attention to the self. Following these authors, a more adult-like version of pointing first emerges through usage and reinforcement around 2 years of age in the linguistic period, a year after its initial emergence.

Gestural origins accounts of human communication and social-pragmatic theories of language acquisition, however, would predict that the gesture not only emerges but is also used with its respective complexities before language. In a series of recent and new experimental studies my colleagues and I have therefore challenged the social-cognitively and social-motivationally 'lean' accounts of infant pointing. We designed different paradigms to elicit and test pointing in 12-month-old infants. In the 'Event'-paradigm, interesting events happened, like a light flashed, a puppet moved, or something appeared from behind a curtain. In the search paradigm, an adult searched for something she needed but could not see. In the request paradigm, infants desired something out of reach. We systematically varied in all these studies the social context, for example what the experimenter saw, liked, knew about, or wanted. Specifically, these studies were designed to challenge the 'lean' hypotheses that (i) infants initially point non-communicatively (Desrochers, Morissette, \& Ricard, 1995); (ii) pointing is nonreferential and does not involve a social-cognitive understanding of the recipients' attention (Moore \& D'Entremont, 2001); and (iii) infants' motivation is mainly egocentric, to obtain objects or attention to the self (Bates et al., 1975; Moore \& D'Entremont, 2001; Gomez, Sarria, \& Tamarit, 1993).

With regard to infants' communicative intent, previous research has mostly measured infants' point accompanying looks to a recipient as an index of their communicative intent. However, for a variety of reasons, gaze alternation is not a valid or reliable indicator of communicative intent (e.g., Moore \& Corkum, 1994; see also Harris, Barlow-Brown \& Chasin, 1995). For example, infants might just be orienting to the adult in response to his behaviours, without communicative intent. Alternatively, they might understand the adult's reaction as communicative even without having to look at him each time. Using instead measures of persistence which test intentions to achieve a certain outcome, we established experimentally that 12month-olds point with the intention to communicate. For example, in the Event-paradigm, when a recipient did not react to infants' pointing, infants persisted in their communicative goal and augmented their signal by repeating their pointing and increasing their vocalizations significantly more than when the adult typically reacted by sharing attention and interest (Liszkowski et al., 2004; 2007a). Even more clearly, before infants initiated a point, they considered whether the recipient attended to them and so could see their point. When an adult turned sideways and did not look at infants (and so could not possibly see the pointing gesture), infants pointed significantly less than when the adult was turned toward them and so could see and react to their visual gesture (Liszkowski, Albrecht, Carpenter, \& Tomasello, 2008). Recently, Franco, Perucchini, and March (2009) further showed that infants point significantly less when the adult is absent compared to when she is present, and that infants do not only point in response to adults but also for peers. Together, these findings thus establish experimentally that 12-month-olds point with the intention to communicate.

With regard to infants' referential intentions, Moore and D'Entremont (2001) claimed that infants do not intend to direct others' attention based on their finding that infants often pointed at things another person was already attending to. However, one can refer to things others are already attending to, for example to express some form of interest in it. In our studies we used again the measure of persistence and established experimentally that infants point with referential intentions to present others with the subject of their communication. In two studies (Liszkowski et al., 2004; 2007a), using again the Event-paradigm, a recipient misidentified infants' referents and either attended solely to the infants' face, or to an irrelevant object nearby the intended referent, both times emoting positively to the infant. In both these cases of referential misunderstandings, infants attempted to redirect the recipient's attention by repeating 
their pointing to their intended referent significantly more often than when the recipient had correctly identified the referent. Further, they vocalized more and looked more often at the experimenter.

In two more recent studies we manipulated the presence or absence of the referent. The underlying reasoning was that referential intentions on a mental level are independent of the perception or presence of the actual referent. Although in deictic communication one generally refers to something present in the environment, it is possible to go beyond the immediate 'here and now' by presenting locations or aspects indicative of the referent. For example, one can point to an armchair and refer to late grandfather who used to sit in it given enough shared background (see also Nunberg, 2004, on deferred reference). Communication beyond the immediate 'here and now' has previously been taken to be a design feature of human language ('displacement', see Hockett, 1963). In our studies, we found that prelinguistic infants already referred to previous events or objects which were not present at the moment of testing. For example, in the Event-paradigm, when infants had attended to an interesting event and it had ceased, they then pointed to its previous, nowempty location depending on how a recipient had reacted to it before (Liszkowski et al., 2007b). Further, in a request-paradigm, to obtain a desirable object that was absent at the moment of request, infants - but not chimpanzees who were tested in the same study design - pointed to the object's mutually known but now-empty location, thus referring to the absent entity (Liszkowski, Schäfer, Carpenter, and Tomasello, 2009). Together, these findings thus establish that infants point with the intention to refer others to specific events and entities, and sometimes even to absent referents.

With regard to infants' motives or reasons why they communicate about specific entities and events, main findings are that infants point for others with cooperative and prosocial instead of purely egocentric motives. Since one may point for various reasons, we investigated different kinds of context, seeking to provide positive evidence for different motives underlying infants' pointing. In the Event-paradigm, we found that infants point at interesting events to share their interest about these events with others. For example, when an adult only oriented to the infant's referent but then did not comment on it (Liszkowski et al., 2004), or when the adult commented about the referent in an unenthusiastic way and communicated to the infant that her interest did not match the infant's interest (Liszkowski et al., 2007a), infants' intention was not satisfied as reflected in their differential pattern of pointing: When the experimenter did not comment at all, infants persisted and repeated their pointing; when the experimenter's comment was uninterested instead of positive, infants did not persist but ceased pointing over trials (although they remained generally interactive with the adult throughout the experiment). Crucially, when the adult already knew about the referent, infants still pointed at it but only if the adult had expressed interest in it, presumably to share and express their alignment with the adult's expression of attitude (Liszkowski et al., 2007b; see also Liebal, Carpenter \& Tomasello, in press). These findings show that infants do not only want to share the visual focus on a referent, they want to express and share their attitudes about a referent, too (what we have termed 'expressive pointing').

In a recent, more natural paradigm we observed parents and infants in a 'decorated room', remotely analogous to a visit in a zoo or exhibit. Parents were instructed to take a look together at the decoration items, with no mentioning of pointing. Findings were that parents and infants spontaneously pointed, and that their pointing was positively correlated (Liszkowski \& Tomasello, submitted). Interestingly, follow-up analyses (Puccini \& Liszkowski, 2009) revealed that a portion of the points were in response to the interlocutors points (within $10 \mathrm{sec}$.) and positively interrelated. The follow-up further showed that infants' degree of joint pointing (as indexed by responsive points) correlated with infants' time spent in manual joint actions in a free play context ('active joint engagement'). These findings provide further support that infants use pointing indeed cooperatively in the shared activity of looking at things together.

However, adults also point for other reasons, for example to provide relevant and needed information for others ('informative pointing'). In 
essence, this kind of pointing is motivated by helping others find things without immediate direct benefit to the pointer. For example, when I see you searching for something, and I see a key under a chair, I will point it out for you, even if I do not know you or have any interest in the key itself. Using a newly developed searchparadigm, we demonstrated for the first time that infants too point to help others by providing them with relevant information. In the studies, when infants were confronted with an adult searching for one of two things, infants pointed to the relevant object to help the adult find it, with no requestive accompaniments or particular interest in the object (Liszkowski et al., 2006), and they did this more so when the adult needed help to find it than when she did not (Liszkowski et al., 2008). More recently, we found that infants also provide information to warn others in anticipation of a negative action outcome (Knudsen \& Liszkowski, 2010). In the study, the experimenter experienced unforeseen negative effects (pain or disgust) when accidentally bumping into an object in the course of her play with marbles. Subsequently she removed the object out of her way. In her absence, someone else accidentally pushed the object back into the way. When the experimenter re-appeared, infants spontaneously pointed out the object, even though the experimenter did not search for anything and the object did not move in interesting ways. Infants pointed significantly less in control conditions, when the object was either positive (thus not evoking negative side effects) or the experimenter had witnessed the location change (and thus the problem was known already). Both, informing others to help them find something, and warning others to help them avoid something are based on a prosocial motivation. Informative pointing and warning may be interpreted as the ontogenetically earliest evidence for altruistic helping without direct benefit for the self.

Infants point of course also with other motives, most prominently to request objects for themselves ('imperative pointing'; Bates et al, 1975). But unlike previous research (e.g., Camaioni, 1993), the claim is that even imperative pointing relies on a cooperative infrastructure of human communication. Evidence is still a bit sparse, but one fundamental difference that distinguishes infants' from apes' requests are infants' referential intentions and communication on a mental level, as revealed by their indirect requests of absent things through pointing to empty locations (Liszkowski et al., 2009). Some other evidence with slightly older children further shows that children do not only want their requests to be fulfilled, but also understood (Shwe \& Markman, 1997; Grosse et al., submitted). Another requestive motive for pointing is to request information ('interrogative pointing'). Several authors have proposed that infants may point interrogatively (Yamada \& Nakanishi, 1983; Baldwin \& Moses, 1996; Liszkowski, 2005; Southgate, van Maanen \& Csibra, 2007) but there is currently little evidence that infants indeed use pointing in this way (but see Kovacs et al., 2010). In sum then, the reasons why infants point at specific events and entities are various. Most, if not all of them involve cooperative and prosocial motives, in particular to align with others and accumulate common ground, or to help others pursue their actions.

With regard to 12-month-olds' social-cognitive understanding, our studies directly tested their understanding of others' intentional and epistemic states. In the Event paradigm, infants understood others' attention as evidenced by significantly more pointing when the adult had not yet seen the event than when she already had. Infants pointing further revealed an understanding of the adult's attitudinal relations to the referent (Liszkowski et al., 2007a, b). In the search paradigm, infants understood an adult's intention to find an object and they understood whether the adult was knowledgeable or ignorant (Liszkowski et al., 2006; Liszkowski et al., 2008). The warning paradigm further clarified that infants anticipate others' actions based on an understanding of their goals and epistemic states, even in the absence of behavioural manifestations like effortful trying or search behaviours (Knudsen \& Liszkowski, 2010). The latter study suggests an emerging belief-desire psychology of action predictions in the service of collaborative communication (see Knudsen \& Liszkowski [submitted] for further evidence of 18-and 24-month-olds' productive usage of 'theory-of-mind'-skills in an anticipatory correcting paradigm). From the comprehension side fur- 
ther studies show that twelve-month-olds comprehend others' pointing in terms of the pointer's underlying referential intentions (Gligia \& Csibra, 2009), and that infants' referential understanding of pointing is bi-directional as evidenced by correlations of infants' point production and their comprehension of pointing to occluded referents (Behne, Liszkowski, Carpenter \& Tomasello, submitted; Liszkowski \& Tomasello, submitted;).

In sum then, recent and new experimental findings provide a new look at infant pointing as a fully communicative act including full fledged reference on a mental level, even to absent entities, with cooperative motives like sharing and helping, all before language has emerged. These findings thus support gestural origins accounts and social-pragmatic theories of human communication. They provide ontogenetic evidence that human communication emerges first in the gestural modality of deictic communication and is based on social-cognitive and motivational skills that run much deeper than language alone.

\section{Emergence of deictic gestures and their relation to language}

The exact process of the emergence of pointing is not well understood at the moment (see also Lock, Young, Service, \& Chandler, 1990). Since pointing is not functional as an object-directed individualistic action (unlike e.g., reaching), and because it is used communicatively with cooperative motives and a social-cognitive understanding from the beginning, pointing does not seem to originate simply from individualistic object-directed actions, in particular not from reaching (see also Franco \& Butterworth, 1996). Presumably, as already suggested by Werner \& Kaplan (1963), the ability to refer originates in interpersonal contexts. That is, it originates from an emerging motive to share objects together as "objectsof-regard". This is supported by correlational findings of spontaneous caregiver and infant pointing (Liszkowski \& Tomasello, submitted) and correlations between caregiver and infant joint acting and joint pointing (Puccini \& Liszkowski, 2009). Whether the particular form of pointing with the index finger arises through imitation or has a more biological basis, is not clear. However, recent results from a comparative study across seven very different cultural settings showed that 12-month-olds pointed with the extended index-finger. This supports the idea that this is a universal gesture (Liszkowski, Brown, Callaghan, deVos, Takida, 2010). Very little is known about the showing gesture in infants, but it may be a precursor to pointing because it emerges before pointing (Bates et al., 1975) and is presumably also found universally across cultures (Salomo \& Liszkowski, 2010). In any case, given the communicative complexities of pointing when it has just emerged, pointing must be conceptualized as developmental accomplishment of - and not a precursor to - referential communication.

Once pointing has emerged, it is interesting to note that its frequency in use still increases over the second year of life (Lock et al., 1990), suggesting that it continues to play a pivotal role in infant communication. Indeed, the onset of pointing is correlated with the onset of first words (Brooks \& Meltzoff, 2008; Carpenter et al., 1998; Harris et al., 1995). Most strikingly, much of infants beginning linguistic communication is complemented through pointing acts. These word+point combinations change in quality over the second year of life. Infants first convey redundant referential information with their point and word (e.g. point to cup and say "cup"). Subsequently, infants convey different, supplemental information elements with their word+point combinations, for example by pointing to the cup and saying "mommy" (Capirci, Iverson, Pizzuto \& Volterra, 1996; Iverson \& Goldin-Meadow, 2005). The latter type of supplemental word+point combinations is even predictive of the onset of the two-word stage around 2 years of age. These developmental findings thus show, in infants, that deictic gestures and spoken words are tightly intertwined. Finally, non-human primates, who never acquire language, and children with autism whose language impairment is both a symptom and a source of their condition, do not point like typically developing children do (e.g., Tomasello \& Camaioni, 1997). This provides further evidence for the tight link between deictic gestures and the emergence of language. 


\section{Other gestures}

The evidence shows that deictic gestures play a main role in infants' prelinguistic communication: They emerge before language; infants use them to communicate in complex ways; and they are tightly coupled with later emerging first words and early syntax. These findings are in strong support of social pragmatic theories and gestural origins accounts of language. However, infants also use a variety of other gestures. In the remainder I will discuss what we currently know about the communicative complexities of these non-deictic, other gestures and what their role is in the emergence of language. Broadly speaking, two core types can be distinguished: ritualized gestures and representational gestures. Ritualized gestures are conceptualized as involving simpler forms of communication and cognition, shared with nonhuman primates (e.g., Tomasello, 2008). Representational gestures are conceptualized as uniquely human forms of symbolic communication, involving more complex representational processes than deictic gestures (e.g., Bates, 1979).

Ritualized gestures originate in individualistic goal-directed action schemes (Tomasello, 2008). For example, the 'hands-up' gesture as a request to be picked up originates in individual attempts to actually climb up. These attempts become abbreviated and stylized in form over time as the interlocutor anticipates and accommodates to the emitter's goal. Since ritualized chains of behaviours are based on behavioural associations, no deeper social-cognitive skills are necessary to understand the goal of a ritualized action gesture. Ritualized gestures also do not involve a bi-directional understanding, because the usage between emitter and recipient is not reversed (e.g., it is only the infant who reaches up - not the adult - and only the adult who picks up - not the infant). Non-human primates learn the majority of their gestures through ontogenetic ritualization (Call \& Tomasello, 2007). Although ritualized gestures look like symbolic codes, in fact they are not, because they are used in a specific way, and because they are not acquired and not used with a bi-directional understanding of re-presenting anything other than the present activity.
In contrast to ritualized gestures - and in contrast to deictic gestures which indicate a referent by means of presenting an aspect in the environment - representational gestures indicate a referent by means of re-presenting a referent with a gesture commonly associated with it. In essence, the gesturer presents a gestural event, and this event is associated with a referent. These associations are usually arbitrary and conventional (socially constructed). Representational gestures are thus symbolic and work just like spoken symbolic words of natural languages. Gestural origins accounts of human communication should predict that these forms of gestural communication emerge prior to spoken language. One question is thus whether there is a modality advantage of symbolic gestures over spoken words.

However, a special feature of representational gestures is that their association with a referent can also be based on some kind of iconic depiction or pantomimic relation. Of course, many iconic gestures are in addition conventionalized, because the gestural depiction of a referent is often not transparent enough and somewhat arbitrary in itself. However, purely iconic gestures are distinct from conventionalized gestures because they can be created and used on the fly - given enough shared background about the aspects they depict! Since purely iconic gestures, just like pointing, do not require the handling of any pre-specified semantic codes, social-pragmatic theories of human communication would predict that they rely on similar social-cognitive skills together with additional cognitive skills of representations. A further question is thus whether infants use creatively invented iconic gestures in representational/symbolic ways before they have acquired any language.

Bates (1979) proposed that infants begin to name things with both words and representational gestures at about the same time, around 13 months of age. This suggests that there is no modality advantage of gestures over words. In a larger sample, in a longitudinal study of infants' naturally occurring gestures and words at 16 and 20 months of age, Iverson, Capirci, and Caselli (1994) found that the number of representational gestures at 16 months was much smaller than the number of representational 
words (25\% of the number of representational words) (see also Capirci et al., 2005). Further, representational gestures decreased at 20 months, while deictic pointing and representational words still increased. Goodwyn and Acredolo (1993) argued that infants are more frequently exposed to words than gestures and conducted a training study to accommodate for this asymmetry. However, the gesture-training yielded only a minor advantage of about 3 weeks in the onset of representational gestures over words (around 14-15 months). In sum, current studies do not provide strong evidence for a modality advantage of representational gestures over words in onset and usage. If anything, they show the reverse pattern with representational gestures emerging after words (Pizzuto \& Capobianco, 2005).

Compared to the bourgeoning studies on pointing, little is yet known about how infants use their representational gestures. In one of the first studies, Acredolo and Goodwyn (1988) conducted longitudinal interviews with parents of 16 infants, beginning at 11 months of age, over a weekly assessment period of 9 months, to document the repertoire and usage of infants' representational gestures. Main findings were that infants used non-deictic gestures that were classified as some form of representational gestures. Following parental interviews, most infants $(75 \%)$ used representational gestures to name objects (e.g., sniffing for 'flower'), sometimes to request actions (e.g., knob-turning for 'open door'; arms-up for 'pick me up'), and to a lesser extent to refer to object attributes (blow for 'hot'; palms up for 'all gone'). These gestures were overall low in frequency and emerged around 14-15 months. Other studies have also considered actions with or without objects as communicative gestures if they were used in some kind of playful or pretend situations (e.g., bringing empty cup to mouth for "drink"; raising empty fist to ear for "telephone") (Caselli, 1990; Capirci et al., 2005). Overall, these studies do not provide strong evidence that infants use the gestures representationally and flexibly across a variety of contexts to refer to specific referents.

But do infants spontaneously create iconic depictions of referents, and if so, to what extent do these emerge prior to language or prior to the acquisition of the corresponding spoken labels? Most studies suggest that the relatively infrequently occurring representational gestures apparently originate in conventional interaction formats and routines and are not spontaneously invented. Although Goodwyn and Acredolo (1988) stressed that about half of infants' object-gestures were not explicitly taught, following parents' report, also these gestures were apparently only used in specific situations (e.g., rubbing tummy for 'soap' when taking a bath). Current studies do not provide strong evidence that young infants spontaneously create iconic gestures to represent a referent. Further, from a comprehension side, Namy (2008) showed that infants understand the iconic depiction of actions only from around 26 months of age, an age at which they already have a considerable vocabulary size.

It is difficult to know about the cognitive underpinnings of infants' representational gesture use without further experimental evidence. Comprehension studies mostly show that young infants associate a range of different non-verbal, verbal and gestural events with specific situations or objects after repeated exposure (e.g. Campbell \& Namy, 2003), but it is unclear whether young infants understand the representational aspects of these events. The production studies currently do not provide evidence that young infants indeed use their representational gestures to $r e$-present anything. Precisely because the reported gestures mostly originate in social routines and conventional formats, an alternative interpretation is that infants initially present with their representational gestures nothing other than their usage itself. In other words, it is possible that infants' 'representational' gestures simple present, but not re-present, infants' participation in social activities.

A thorough-going lean position might claim the same for infants' first words. However, it is also possible that the symbolic usage of words is acquired more easily than that of representational gestures. Words are by default used to represent a referent. Gestures instead rely on action schemes, and actions, by default, are used to act on the world, not to represent it. Symbolic gesture-use thus requires decoupling the action schema from an action goal and re-interpreting it as standing in for something else (Leslie, 
1987). The cognitive argument is thus that the symbolic usage of representational gestures is initially even more challenging than using words. Research on infants' cognitive development suggests that children develop a representational understanding around age two, when they creatively extend pretend scenarios (Harris \& Kavanaugh, 1993), map scale-models to the real world (DeLoache, 2004), and understand pictorial symbols (Preissler \& Carey, 2004).

\section{Other gestures and their relation to language}

With regard to the developmental relations between other gestures and language, converging evidence shows that infants initially do not combine their 'representational' gestures with words or points (Capirci et al., 1996; Iverson \& Goldin-Meadow, 2005; Pizzuto \& Capobianco, 2005). This is striking when compared to infants' frequent combinations of deictic pointing gestures with words in those same studies. Infants thus use their representational gestures quite differently from adults who frequently accompany them with speech (McNeill, 1992; Kendon 2004). Representational gestures also do not predict, to the best of my knowledge, the onset of first words, which is again in stark contrast to several studies showing relations between deictic gestures and the emergence of language (Brooks \& Meltzoff, 2008; Carpenter et al., 1998; Harris et al., 1995). Indeed, it is unknown whether the absence of infant representational gestures would significantly impact early language acquisition, while the absence of pointing in fact is diagnostic of early autism (Baron-Cohen, 2000).

It is not entirely clear whether infants know the spoken labels for at least some of their gestures, and to what extent spoken and gestural labels correspond to each other (but see Capirci et al, 2005). But curiously, research on older children shows that it is around 2 to 3.5 years of age that children frequently begin to accompany their speech with iconic gestures, similar to adults, and that the meaning matches between the two modalities (Nicoladis et al., 1999). Nicoladis and colleagues investigated speech accompanying gestures in five bilingual children and found that the occurrence of speech and iconic gesture combinations were influenced by the proficiency of the language with which the gestures were used. This finding indicates a relation between iconic gestures and language that is in fact the reverse of what gestural origins of language and 'language-from-action' accounts would predict. The currently available evidence and the argument from cognitive complexities underlying the manual use of symbolic actions may thus suggest that representational and iconic gestures rather emerge through language - as symbolic actions - and not the other way around.

\section{Conclusion}

Around twelve month of age, human infants begin to communicate in meaningful ways through gesture, already before they have developed any productive language skills. Infants' communication rests on the basic psychological foundations of adult human communication, that is, a cooperative motivation to interact with each other, together with a social-cognitive understanding of others' mental agency. This psychological infrastructure enables prelinguistic infants to express and understand communicative, referential, and social intentions within shared situations. Using the single pointing gesture, infants communicate a wealth of information. Although it is 'only one' gesture, this is less surprising when considering that one can express a myriad of different things with pointing precisely because it is entirely deictic and not symbolically codified. Findings show that infants, like adults, use the pointing gesture within shared common ground even to refer to occluded entities and entities that are absent from mutually known locations. Infants' usage of pointing is thus much broader than simple conceptions of attention directing to discrete, perceivable objects in space. Developmentally, infants' pointing is closely linked to language acquisition, and its absence or aberrant development are, for example, both a symptom and a source of autism disorder. Thus, in support of gestural origins and social-pragmatic accounts of human language, there is a solid fundament of gestural, deictic communication already be- 
fore language has emerged. This kind of gestural deictic communication, however, means that even though displacement and reference beyond the 'here and now' are possible, infants' communication is still fully dependent on visually shared situations.

But infants also use several other gestures. These have been described as ritualized gestures, shared with non-human primates, and as representational gestures, part of uniquely human symbolic communication. The question has been to what extent infants use these other gestures symbolically, in particular those gestures that have been described as representational, and to what extent these gestures indeed constitute a "second dawn" in infants' communicative development (Bates, 1979). A review of the current findings suggests that representational gestures play a rather minor role in the transition to representational spoken language and, to date, little is known about the cognitive complexities underlying infants' usage of representational gestures. One may indeed wonder whether their absence would significantly impact language acquisition. Based on the available empirical evidence it is plausible that infants initially use these gestures as participatory activities that present infants' usage, but do not necessarily re-present anything other than the gestural social activity itself. Arguments about the cognitive requirements and findings of a late emerging gesture-speech integration give rise to the idea that representational gestures rather constitute a "third dawn", after language, when children come to understand that they can use manual actions to represent things (instead of acting on things). These findings thus shed a differentiated perspective on gesture in the origins of language and suggest that some gestures even emerged after auditory, spoken forms of communication.

Language often underdetermines what is actually being communicated. Deictic communication is the example par excellence (see Levinson, 2004), because deictic communication cannot be interpreted based on codified meanings, but only through mutually shared background coordinates and an understanding of others' communicative intentionality. I have presented evidence that the underlying immense psychological complexity is not a developmental result of, but the starting point for human com- munication. The findings of an ontogenetic primacy of deictic gestural over symbolic spoken communication reveal the force of gesture in the evolution of language. However, the ontogenetic evidence forces us to consider that it is not gestures generally that take the lead in the emergence of language. Instead, the use of representational action schemes is a later achievement, and it is plausible that it is even mediated by language. Thus, it is deictic gestures specifically - not gestures generally - that are the stepping stone to uniquely human forms of symbolic communication. Deictic gestures, which emerge already a year after birth and pertain across life in the single quotidian, uniquely human and universal form of pointing.

\section{Acknowledgements}

I am thankful to Susan Schmidt and Adam Kendon for comments on an earlier draft.

\section{References}

Acredelo, L.P., \& Goodwyn, S.W. (1988). Symbolic gesturing in normal infants. Child Development, 59, 450-466.

Arbib, M.A., (2005). From Monkey-like Action Recognition to Human Language: An Evolutionary Framework for Neurolinguistics. Behavioral and Brain Sciences. 28, 105-167.

Archer, D. 1997. "Unspoken Diversity: Cultural Differences in Gestures." Qualitative Sociology, 20.

Armstrong, D.F. \& Wilcox, S.E. (2007). The Gestural Origin of Language. New York: Oxford University Press.

Baldwin, D.A., \& Moses, L.J. (1996). The ontogeny of social information gathering. Child Development, 67, 1915-1939.

Baron-Cohen, S. (1989). Perceptual role taking and protodeclarative pointing in autism. British Journal of Developmental Psychology, 7(2), 113-127.

Baron-Cohen et al. (2000). Early identification of autism by the CHecklist for Autism in Toddlers (CHAT). Journal of the Royal Society of Medicine, 93, pp. 521-525. 
Bates, E. (1979). The emergence of symbols: Cognition and communication in infancy. New York: Academic Press.

Bates, E., Camaioni, L., \& Volterra, V. (1975). The acquisition of performatives prior to speech. Merrill-Palmer Quarterly, 21, 205-226.

Behne, T., Liszkowski, U., Carpenter, M., Tomasello, M. (submitted). Twelve-month-olds' comprehension and production of informative pointing in a hiding-finding game.

Brooks, R., \& Meltzoff, A. N. (2008). Infant gaze following and pointing predict accelerated vocabulary growth through two years of age: A longitudinal, growth curve modeling study. Journal of Child Language, 35, 207-220.

Bruner, J. (1983). Child's talk. New York: Norton.

Call, J. \& Tomasello, M. (2007). The gestural communication of apes and monkeys. New York: LEA.

Camaioni, L. (1993). The development of intentional communication: a re-analysis. In Nadel, Jacqueline, Camaioni, L. (Eds.). New perspectives in early communicative development. London: Routledge, 82-96.

Campbell, A.L \& Namy, L. L. (2003). The role of social-referential context in verbal and nonverbal symbol learning. Child Development, 74(2), 549563.

Caselli, MC. (1990). Communicative gestures and first words. In: Volterra V, Erting CJ (Eds.) From gesture to language in hearing and deaf children. Berlin: Springer Verlag. Washington, DC: Gallaudet University Press, pp. 56-67.

Capirci, O., Contaldo, A., Caselli, M., Volterra, V. (2005). From action to language through gesture: A longitudinal perspective. Gesture, 5(1-2), 155177.

Carpenter, M., Nagell, K., \& Tomasello, M. (1998). Social cognition, joint attention, and communicative competence from 9 to 15 months of age. Monographs of the Society of Research in Child Development, 63(4), Serial No. 176.

Clark, H. (1996). Uses of language. Cambridge: Cambridge University Press.

Corballis, M. C. (2002). From Hand to Mouth: The Origins of Language. Princeton University Press.
DeLoache, J. S., (2004). Becoming symbol-minded. Trends in Cognitive Sciences, 8, 66-70.

Desrochers, S., Morissette, P., \& Ricard, M. (1995). Two perspectives on pointing in infancy. In C. Moore \& P. J. Dunham (Eds.), Joint attention: Its origins and role in development (pp. 85-101). Hillsdale, NJ: Lawrence Earlbaum.

Franco, F., \& Butterworth, G. (1996). Pointing and social awareness: Declaring and requesting in the second year. Journal of Child Language, 23, 307-336.

Franco, F., Perucchini, P., \& March, B. (2009). Is infant initiation of joint attention by pointing affected by type of interaction? Social Development, 18, 51-76.

Gliga, T. \& Csibra, G. (2009). One-year-old infants appreciate the referential nature of deictic gestures and words. Psychological Science, 20, 347-353.

Gomez, J. C., Sarria, E., \& Tamarit, J. (1993). The comparative study of early communication and theories of mind: Ontogeny, phylogeny, and pathology. In S. Baron-Cohen, H. Tager-Flusberg, \& D. J. Cohen (Eds.), Understanding other minds: Perspectives from autism (pp. 397-426). New York: Oxford University Press.

Goodwyn, S., \& Acredolo, L. (1993). Symbolic gesture versus word: Is there a modality advantage for onset of symbol use? Child Development, 64, 688-701.

Grosse, G., Behne, T., Carpenter, M., Tomasello, M. (submitted). Wanting to be understood: The cooperative and mental nature of infant requests.

Harris, M., Barlow-Brown, F. \& Chasin, J. (1995). The emergence of referential understanding: pointing and the comprehension of object names. First Language, 15, 19-34.

Harris, P. L., \& Kavanaugh, R. D. (1993). Young children's understanding of pretense. Monographs of the Society for Research in Child Development, 58(1)[231]), v-92.

Hockett, C.F. (1960). The origin of speech. Scientific American, 203, 88-96.

Iverson, J.M., Capirci, O., \& Caselli, M.C. (1994). From communication to language in two modalities. Cognitive Development, 9, 23-43.

Iverson, J. M., Goldin-Meadow, S. (2005) Gesture Paves the Way for Language Development. Psychological Science, 16(5), 367-371. 
Kendon, A. (2004). Gesture. Visible action as utterance. Cambridge University Press.

Knudsen, B. \& Liszkowski, U. (submitted). Infants helpfully correct other persons in anticipation of action mistakes.

Knudsen, B. \& Liszkowski, U. (2010). 12- and 18month-old infants warn others in anticipation of negative action outcomes. Poster presented at the International Conference on Infant Studies.

Kovacs, A.M., Tauzin, T., Csibra, G., Gergely, G. (2010). Why do 12-Month-olds Point? Desire to Learn vs. Desire to Share Interest. Poster presented at the International Conference on Infant Studies.

Leslie, A. M. (1987). Pretense and representation: The origins of "theory of mind." Psychological Review, 94(4), 412-426.

Leung \& Rheingold, (1981). Development of pointing as a social gesture. Developmental Psychology, 17 (2), 215-220.

Levinson, S. C. (2004). Deixis. In L. Horn (Ed.) The handbook of pragmatics (pp. 97-121). Oxford: Blackwell.

Liebal, K., Carpenter, M., \& Tomasello, M. (in press). Infants' use of shared experience in declarative pointing. Infancy.

Liszkowski, U., Schäfer, M., Carpenter, M., \& Tomasello, M. (2009). Infants but not apes point to refer to absent things before language.

Liszkowski, U., Carpenter, M., Tomasello, M. (2008). Twelve-month-olds provide information to help an adult find what she is looking for.

Liszkowski, U., Albrecht, K., Carpenter, M., Tomasello, M. (2008). Twelve-and 18-month-olds' visual and auditory communication when a partner is or is not visually attending.

Liszkowski, U., Carpenter, M., \& Tomasello, M. (2007a). Reference and attitude in infant pointing. Journal of Child Language.

Liszkowski, U., Carpenter, M., Tomasello, M. (2007b). Pointing out new news, old news, and absent referents at 12 months of age. Developmental Science, 10(2). F1-F7.

Liszkowski, U., Carpenter, M., Striano, T., \& Tomasello, M. (2006). Twelve- and 18-month-olds point to provide information for others. Journal of Cognition and Development 7(2), 173-187.

Liszkowski, U., Carpenter, M., Henning, A., Striano, T., \& Tomasello, M. (2004). Twelve- month-olds point to share attention and interest. Developmental Science, 7(3), 297-307.

Lock, A., Young, A., Service, V., \& Chandler, P. (1990). Some observations on the origins of the pointing gesture. In V. Volterra \& C.J. Erting (Eds.), From gesture to language in hearing and deaf children (pp. 42-55). Berlin: Springer-Verlag.

McNeill, D. (1992). Hand and mind. What gestures reveal about thought. Chicago, University of Chicago Press.

Moore, C., \& Corkum, V. (1994). Social understanding at the end of the first year of life. Developmental Review, 14, 349-372.

Moore, C., \& D'Entremont, B. (2001). Developmental changes in pointing as a function of attentional focus. Journal of Cognition \& Development, 2, 109129.

Murphy, C. M. (1978). Pointing in the context of a shared activity. Child Development, 49(2), 371-380.

Nunberg, G. (2004). The pragmatics of deferred interpretation. In L. Horn \& G. Ward (Eds.), Handbook of pragmatics (pp. 344-364). Malden, MA: Blackwell.

Nicoladis, E., Mayberry, RI, \& Genesee, F. (1999). Gesture and early bilingual development. Developmental Psychology, 35, 514-526.

Pizzuto, E., Capobianco, M. (2005). The link and differences between deixis and symbols in children's early gestural-vocal system. Gesture, 1-2, 179-199.

Preissler, M.A. \& Carey, S. (2004). Do both pictures and words function as symbols for 18- and 24month old children? Journal of Cognition and Development, 5, 185-212.

Puccini, D. \& Liszkowski, U. (2009). Joint action and joint pointing at 12 months. Poster presented at the 3rd Joint Action Meeting, Amsterdam, The Netherlands.

Quine, W. (1960). Word and object. Cambridge, MA: Harvard University Press.

Salomo, D. \& Liszkowski, U. (2010). Caretaker-infant social interaction and gestures across cultures. 
Poster presented at the International Conference on Infant Studies.

Shwe, H. I., \& Markman, E. M. (1997). Young children's appreciation of the mental impact of their communicative signals. Developmental Psychology, 33(4), 630-636.

Southgate, V., van Maanen, C., \& Csibra, G. (2007). Infant pointing: communication to cooperate or communication to learn? Child Development, 78 (3), 735-740.

Sperber, D. \& Wilson, D. (1986). Relevance: Communication and cognition. Oxford: Blackwell.

Tomasello, M. (2008). Origins of Human Communication. MIT Press.
Tomasello, M., \& Camaioni, L. (1997). A comparison of the gestural communication of apes and human infants. Human Development, 40, 7-24.

Tomasello, M., Carpenter, M., \& Liszkowski, U. (2007). A new look at infant pointing. Child Development, 78, 705-722.

Werner, H., \& Kaplan, B. (1963). Symbol formation: An organismic-developmental approach to language and the expression of thought. New York, Wiley.

Yamada, Yoko; Nakanishi, Yuri (1983). The development of pointing during infancy. Japanese Journal of Child and Adolescent Psychiatry, 24(4), 239-259. 